\title{
EFICÁCIA DO FEMBENDAZOLE NO CONTROLE DE NEMATÓDEOS DE PACU Piaractus mesopotamicus (Holmberg, 1987) ${ }^{1}$
}

\author{
THE EFFICIENCY OF FEMBENDAZOLE IN THE CONTROL OF NEMATODES \\ IN PACU Piaractus mesopotamicus (Holmberg, 1987)
}

\section{Jorge Erick Garcia Parra ${ }^{2}$ Deodoro Atlante Brandão ${ }^{3}$ Paulo Sérgio Ceccarelli ${ }^{4}$}

\section{RESUMO}

\begin{abstract}
O presente trabalho foi realizado no Centro de Pesquisa e Treinamento em Aquicultura (CEPTA/1BAMA), município de Pirassununga, SP. Foram utilizados 60 pacus, dos viveiros da Estação de Piscicultura do CEPTA, com peso médio de 600g. Foi realizado um teste visando avaliar o efeito do Femben-dazote (adicionado no alimento em diferentes dosagens), sobre os nematódeos presentes no tubo intestinal do pacu, utilizando três tratamentos: Tl - grupo testemunha (ração sem Fembendazole), T2 - 20mg de Fembendazole/kg de ração e T3 - 40mg de Fembendazo-le/kg de ração. $O$ delineamento foi inteiramente casualizado. A unidade experimental foi o peixe. Não houve diferença significativa $(P s$ $0,05)$ entre os tratamentos com anti-helmintico Fembendazole nas dosagens de 20mg/kg e 40/ng/kg de ração e o grupo testemunha.
\end{abstract}

Palavras-chave: anti-helmintico, peixe, viveiros.

\section{SUMMARY}

Th is study was done at lhe Agricultural Centre for Training and Research (CEPTA/IBAMA) $m$ the municipality of Pirassununga, São Paulo. Sixty pacus, wilh an average weight of $600 \mathrm{~g}$ were obtained from the nurseries of the fish station at CEPTA. An experiment to determine the ejfect of fenbendazole (added to the ration in various doses) on nematodes in the alimentary canal ofthe pacu was realized using three treatments. Tl - contrai group (ration without fenbendazole, T2 - 20mg fenbendazole/kg ration, and T3 - 40mgfenbendazole/kg ration. The experimental oü̈ine was totally random. The fish was the experimental unit. There was no significam dijference $(P>0.05)$ befween the treatments wilh the anti-helminthic fenbendazole added to the ration in doses of 20 and $40 \mathrm{mg} / \mathrm{kg}$ and the contrai group.

Key words: anti-helminthic, fish, nurseries.

\section{INTRODUÇÃO}

O desenvolvimento acelerado da piscicultura está fazendo com que no Brasil haja uma maior utilização de espécies nativas. O pacu (Piaractus mesopotamicus), é uma espécie que se apresenta como uma boa alternativa por suas características zootécnicas, valor comercial e adaptação a temperaturas irregulares (BERNARDINO \& FERRARI, 1986).

$\mathrm{Na}$ medida em que se tem intensificado as atividades de cultivo, detecta-se maior susceptibilidade dos pacus frente a diversos organismos patológicos. Estes organismos podem causar retardo no crescimento, enfermidades e mortalidade, dependendo do estado do peixe (CONROY, 1989).

\footnotetext{
${ }^{1}$ Parte da Dissertação de Mestrado apresentada pelo primeiro autor ao Curso de Pós-graduação em Zootecnia da Universidade Federal de Santa Maria (UFSM).

${ }^{2}$ Zootecnista, Mestre em Zootecnia.

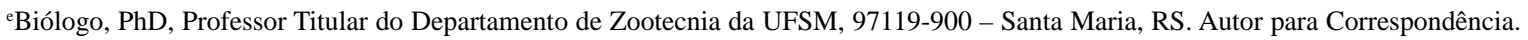

${ }^{\mathrm{r} B i o ́ l o g o, ~ M e s t r e, ~ p e s q u i s a d o r ~ d o ~ C e n t r o ~ d e ~ P e s q u i s a ~ e ~ T r e i n a m e n t o ~ e m ~ A q u ̈ a c u l t u r a ~(C E P T A), ~ P i r a s s u n u n g a, ~ S a ̃ o ~ P a u l o . ~}$
} 
É muito comum encontrar o pacu infectado por nematódeos. Estes são organismos de simetria bilateral que comumente parasitam peixes e podem ocorrer tanto na forma larval como adulta, em peixes de água doce ou marinhos. Normalmente são encontrados no estômago, intestino ou cavidade abdominal. As formas larvais podem ocorrer em quase todos os tecidos do peixe (STOSKOPF, 1993). Os danos causados pelo nematódeo para o peixe varia grandemente, dependendo das espécies presentes, órgão invadido e o número de parasites envolvidos (TATCHER, 1991).

Nematódeos que se encontram em peixes como hospedeiro intermediário, podem causar maiores lesões que os encontrados na forma adulta, porque estas formas afetam principalmente os tecidos. Nematódeos adultos raramente causam severos danos, normalmente induzem a lesões locais de pouca significância para a saúde geral do peixe hospedeiro (KABATA, 1985).

No Brasil têm sido feitos levantamentos identificando os nematódeos presentes no pacu, KOHN et al. (1985), descreveram o nematódeo Rondonia rondoni em viveiros do CEPTA. Assim CECCARELLI \& OLIVEIRA (1986), observaram num levantamento feito nos rios do pantanal de Mato Grosso o nematódeo $\boldsymbol{R}$. rondoni em todos os peixes necropsiados sempre em grande quantidade. Tem sido reportado também o nematódeo Spectatus spectatus infestando o pacu, em pequeno número e associado a $R$. rondam (HAMMAN, 1982; KOHN et al., 1985 e CECCARELLI \& OLIVEIRA, 1986).

O nematódeo $R$. rondoni além do pacu Piaractus mesopotamicus, tem sido encontrado em Colossoma macropomum e Piaractus brachipomus (CONROY (1989); em Myletes torquatus, Doras granulosus e Myleus sp (TRAVASSOS et al., 1928). Apesar de ter encontrado os pacus infectados em grandes quantidades, FIGUEIRA \& CECCARELLI (1991), constatam que os produtores piscícolas não utilizam tratamento profilático nem terapêutico.

Diferentes tipos de drogas podem ser utilizadas para combater os nematódeos, mas sua eficácia depende da capacidade destes organismos resistir a diferentes dosagens do anti-helmíntico, ou a droga não ter efeito no seu modo de ação no nematódeo (BOOTH $\&$ McDONALD, 1992).

Geralmente os anti-helmínticos podem ter diferentes modos de ação sobre os nematódeos, alguns compostos bloqueiam a ação da redutase do fumarato inibindo a geração de energia mitocondrial na forma de ATP, ou inibindo o transporte da glicose (BOOTH
\& McDONALD, 1992). O Fembendazole é um antihelmíntico que pertence ao grupo dos Benzimidazois, que atuam sobre os nematódeos interferindo no seu metabolismo gerador de energia, pois na ausência de energia utilizável o nematódeo morre (BOOTH \& McDONALD, 1992).

Tendo em vista o grande número de nematódeos encontrados no meio natural e em piscigranjas, e por não ter sido feito nenhum tratamento profilático nem terapêutico pêlos produtores piscícolas, este trabalho teve como objetivo determinar a eficácia do Fembendazole para controlar os nematóides do pacu Piaractus mesopotamicus.

\section{MATERIAIS E MÉTODOS}

O trabalho foi desenvolvido no Centro de Pesquisa e Treinamento em Aquicultura CEPTA/ IBAMA, no período compreendido entre outubro a dezembro de 1995. Foram utilizados 60 pacus (Piaractus mesopotamicus), que já vinham sendo alimentados com ração, com peso médio de $600 \mathrm{~g}$. Estes peixes foram distribuídos em seis tanques de fibra de vidro, com capacidade para 3000 litros cada, sendo um peixe para cada 300 litros, utilizando taxa de renovação de sete litros/minuto.

Os peixes foram coletados com ajuda de redes de arrasto. Foram feitas medições biométricas com ajuda do ictiômetro para o comprimento e balança para a pesagem. Foi administrada ração com $22 \%$ de PB, na forma de "pellets". A quantidade oferecida foi de $0,5 \%$ da biomassa (para forçar a ingestão pela fome), fornecida duas vezes por dia, durante 10 dias de tratamento.

Foram utilizados os seguintes tratamentos:

Tl - Ração sem anti-helmíntico -testemunha

(20 peixes); T2 - Ração com anti-helmíntico - 20mg/ $\mathrm{kg}$ de ração (20 peixes); e T3 -Ração com antihelmíntico - $40 \mathrm{mg} / \mathrm{kg}$ de ração (20 peixes).

Após o décimo dia do início do experimento, foram coletados os peixes de cada tratamento, e através de necropsias, observou-se aspecto do peixe, do aparelho digestivo em geral, cor do fígado, localização dos nematódeos dentro do intestino ou reto e contagem dos nematódeos encontrados.

Foi utilizado delineamento inteiramente casualizado. A unidade experimental foi o peixe, os parâmetros estimados foram intensidade e intensidade média. Os dados obtidos foram analisados utilizando o pacote estatístico SAS, foi feita análise de variância e teste Duncan ao nível de significância de 5\%. 


\section{RESULTADOS E DISCUSSÃO}

O produto Fembendazole não foi eficaz no tratamento contra o nematódeo Rondonia rondam. Não houve diferença significativa (P ï 0,05) nos índices parasitários entre os tratamentos $\mathrm{Tl}$ - grupo testemunha, T2 - $20 \mathrm{mg}$ de Fembendazole/kg de ração e T3 - 40mg de Fembendazole/kg de ração (Tabela 1). No que se refere a tratamentos com anti-helmínticos para peixes, pouca bibliografia é encontrada. A maior parte de experimentos e pesquisas sobre tratamentos para eliminar os nematódeos de peixes, utiliza os produtos que se encontram no mercado para outros tipos de animais.

O presente experimento baseou-se, quanto à dosagem, no que se reporta no livro de STOSKOPF (1993), que recomenda a utilização de Fembendazole na dose de $11 \mathrm{mg} / \mathrm{kg}$ misturados na ração, não especificando a espécie de peixe testado, nem os géneros de nematódeos para os quais é efetivo. No Brasil, para espécies de peixes nativas nenhum trabalho sobre tratamento para nematódeos foi encontrado na literatura.

Alguns autores recomendam outros produtos químicos no combate contra nematódeos em peixes. ROBERTS (1981), recomenda óxido de di-n-butil estanho, em dosagens de $25 \mathrm{~g} / 100 \mathrm{~kg}$ de peixes durante 3 dias, misturado na ração, não especificando o peixe. HOFFMANN \& MAYER (1974), recomendam Santonin 0,04g/peixe, contra Contracaecum bidentatum em Acipenser sp, Masoten 1-2ppm para Philometra spp em Cyprinus carpia, Drying para Raphidascaris $\boldsymbol{s p}$ não especificando o peixe.

REICHENBACH-KLINKE (1975) recomenda Mansonil 500g/100kg de ração a 1,5\% do peso vivo no viveiro em carpas e trutas para Philometra. A

Tabela 1 - Intensidade média de Rondonia rondoni nos tratamentos com o uso de Fembendazole.

\begin{tabular}{cccc} 
TRATAMENTOS & $N^{*}$ DE PEIXES & INTENSIDADE* & $\begin{array}{c}\text { INTENSIDADE } \\
\text { MÉDIA** }\end{array}$ \\
\hline & & & \\
1 & 20 & 109569 & 5766,7 \\
2 & 20 & 216956 & 11418,7 \\
3 & 20 & 142835 & 7141,7 \\
\hline
\end{tabular}

Teste de Duncan $\left(P_{2}=0,05\right)$;

* Intensidade = número de nematódeos em cada peixe parasitado;

* Intensidade média = número total de nematódeos encontrados na amostra de $\boldsymbol{P}$. mesopotamicus, dividido pelo número total de peixes parasitados na amostra (média de nematódeos por peixe parasitado).
FAO (1991), recomenda niclosamida para helmintos intestinais em geral.

\section{REFERÊNCIAS BIBLIOGRÁFICAS}

BERNADINO, G, FERRARI, V.A. Efeitos da fertilização na produção de pacu, Colossoma mitret, alimentados com ração. In: SÍNTESE DOS TRABALHOS REALIZADOS COM ESPÉCIES DO GÉNERO COLOSSOMA. Pirassununga, CEPTA, 1986. p. 18

BOOTH, N., McDONALD, L.E. Farmacologia e terapêutica em veterinária. Rio de Janeiro: Guanabara Koogan, 1992. 997 p.

CECCARELL1, P.S., OLIVEIRA, C.A. Ocorrência de helmintos, parasites de Colossoma milrei Ber, 1985 em ambiente natural. IV SIMBRAQ, Associação Brasileira de Aquicultura, Ribeirão Preto, p. 203-205, 1986.

CONROY, D.A. Resefla sobre las principales enfermedades infecto contagiosas y parasitose de peces dei gênero "Colossoma". In:

Cultivo de Colossoma. Bogotá: Guadalupe, 1989. p. 93-112 e 351353.

FAO - Organizacion de Ias Naeiones Unidas para Ia Agricultura y Ia Alimentacion. Manual para Ia prevención y el tratamiento de enfermedades de peces de cultivo de agua dulce. Santiago de Chile, 1991.

FIGUEIRA, L.B., CECCARELLI, P.S. Observações sobre a presença de ectoparasitas em psciculturas tropicais de interior (CEPTA e Região). Boletim Técnico do CEPTA, Pirassununga, v. 4, n. 1, p. 57-61. 1991 .

HAMANN, M.I. Parasitos dei pacu (Colossoma initrei) dei rio Paraná médio. Republica Argentina (Pisces, Serrasalmidae). Historia Natural, n. 2, p. 153-160, 1982.

HOFFMANN, G.L., MEYER, F.P. Parasites offreshwater fishes. Hepherdstown: Shepherd College, 1974.

KABATA, Z. Parasites and diseases of fish cultured in the tropics. London: Taylor\& Francis, 1985. $318 \mathrm{p}$.

ROBERTS, R.J. Patologia de los peces. Madrid: Mundi Prensa, 1981.

STOSKOPF, M.K. Fish medicine. Philadelphia: Saunders Company, 1993. 882 p.

THATCHER, V.E. Amazon fish parasits. Manaus: Instituto Nacional de Pesquisas da Amazônia-INPA-DBA, $1991.571 \mathrm{p}$.

TRAVASSOS, L., ARTIGAS, P., PEREIRA, C. Fauna helmintológica dos peixes de água doce do Brasil. Instituto Oswaldo Cruz e Arch. Instituto Biologia São Paulo, p, 568, 1928. 